\title{
The clinical and serological diagnosis of Mycobacterium bovis in blood and milk serums of lactating cows by IDEXX ELISA test in Wasit and Dhi-Qar provinces/Iraq
}

\author{
Hams Hussain Hashim Al-Fattli
}

Pharmacy College, Al-Qadisiyah University, Al-Qadisiyah, Iraq.

Correspondence to Hams Hussain Al-Fattli (email: hamshussainhashim@gmail.com).

(Submitted: 15 May 2016 - Revised version received: 29 June 2016 - Accepted: 1 July 2016 - Published online: 26 September 2016)

\begin{abstract}
Objectives This study was conducted to disclose the specific antibodies against M. bovis of bovine tuberculosis (bTB) in blood and milk serum samples, with detection of the most prevalent clinical signs in positive cows.

Methods In some rural areas of two Iraqi provinces (Wasit and Dhi-Qar), 119 lactating cows were submitted to the clinical examination with obtaining of blood and milk to tested by using the IDEXX ELISA test.

Results The overall seroprevalence in blood and milk was (20.16\%) and (15.12\%), respectively. In Wasit, the prevalence was (22.85\%) and (15.71\%), while in Dhi-Qar, the prevalence was (16.32\%) and (14.28\%) in blood and milk, respectively. As well as, marked significant differences in seroprevalence were observed between and within the two study's provinces and samples. According to clinical examination, a significant rising $(P>0.05)$ was revealed in respiratory disorders, decreasing in milk production, emaciation, rough hair coat and repetitive reproductive problems, whilst a significant decreasing $(P<0.05)$ in persistent feces abnormalities, mastitis, lymph nodes enlargement and loss of appetite.

Conclusion The study demonstrated, for the first time in Iraq, the efficient of IDEXX ELISA, as a screening test in the detection of bTB in lactating cows by using blood and milk serum samples, and the competence of milk, as sample, in exhibition of infection. Also, the study exposed the high infection rate of bTB in cows of rural areas of Wasit and Dhi-Qar provinces.

Keywords Mycobacterium bovis, lactating cows, IDEXX ELISA, Clinical and serological, Wasit and Dhi-Qar, Iraq
\end{abstract}

\section{Introduction}

Bovine tuberculosis (bTB) is a chronic debilitating infectious disease of domestic and wild animals as well as humans, which is generated by very slow growing bacilli, Mycobacterium bovis. ${ }^{1,2}$ bTB has no geographical boundaries and existing in most developing countries with an inadequate or unavailable surveillance control activities. ${ }^{3}$ Although, bTB manifested, essentially, by a respiratory symptoms, the disease may be found in lymph nodes, intestine, liver, kidneys, bones and central nervous system; resulting in a different clinical signs depending on the site of lesions. ${ }^{4,5}$ Cattle are, extremely, liable to become infected with $M$. bovis in first live by long subclinical phase without or with short interrupted shedding, and terminated in an advance disease with symptoms in a slight rate of diseased cattle. ${ }^{6,7}$ So, the diseased cows are the main source for infection to spread it by inhalation, ingestion and drinking of contaminated water or infected milk. ${ }^{1}$ The precise routes of transmission and genealogical significance of infective paths have not been determined because the disease diagnosis had, broadly, been focused on diseased animals that have a scandalous apparent damage. ${ }^{8}$ In cattle, the damage, firstly, evidenced in respiratory system as granulomatous lesions, then, it may spread to localize in other parts, involved udder to aggregate and calcified causing in mastitis. ${ }^{9}$ In industrialized countries, bTB monitoring with removal schedules, and milk pasteurization had drastically decreasing in extent of infection in both cattle and human. ${ }^{10}$ Iraq is one of these countries that many of the epidemiological and public health aspects of the disease remaining, in general, undetermined. ${ }^{11,12}$

bTB is intractable by scarcity of the feasible techniques and presence of reservoirs; and distribution of it in most areas. ${ }^{13}$ The accurate diagnosis for bTB is essential; for control, eradication, treatment of affected individuals and prevents transmission of infection to humans. ${ }^{14}$ The control strategy that used in most countries through using a single or comparative tuberculin skin test, which depended mainly on the basis of delayed hypersensitivity reactions, is not effective in the diagnosis of infection in first and in terminal stages. ${ }^{15}$ Antibody responding to bacteria showed an invariably related to the mycobacterial emerged pathology and antigen burden. ${ }^{16}$ Thus, the development of serological techniques was increasing a point of diagnosis of the diseased cattle and act as a complementary to tuberculin test. ${ }^{17}$ In addition, multiple tests, if used, might increase the total diagnostic power by detecting the subclinical cases of infected animals that missed by skin test. ${ }^{18}$ In addition to easiness of sample obtaining with technique procedures, the technique can apply in several purposes to supply an extra experiment chances didn't provided by other tests. ${ }^{19}$ IDEXX M. bovis antibody kit is a new serological and commercial ELISA test that manufactured by IDEXX Laboratories to detect the infection in blood, or milk of cows. ${ }^{20}$ It's validated and certified by OIE in 2012 with Approval number of 20120107. ${ }^{21}$ This test is easy to use, cost effective for surveillance, and the need for a little time. ${ }^{19,22}$ The aims were:

1. Estimating the IDEXX ELISA, under field conditions, in diagnosing of infected lactating cows by using the milk and blood serum samples, for the first time in Iraq.

2. The comparison, in accuracy, between blood and milk serum samples in detection of bTB.

3. Providing the more practical and actual morbidity rate for bTB in cows of Wasit and Dhi-Qar provinces.

4. Identification the relationships between clinical signs and positive cases. 


\section{Materials and Methods}

\section{Samples and Data Collection}

A total of 119 lactating cows were submitted to this study, 70 cows from different rural areas of Wasit province and 49 cows from different rural areas of Dhi-Qar province/ Iraq, between August 2015 and March 2016. The data of case history were recorded in depending on clinical examination and owner's information. Under aseptic condition, from each cow, $10 \mathrm{ml}$ blood sample from jugular vein was collected by using a vacutainer syringe, and $50 \mathrm{ml}$ milk sample was collected by manual milking into plastic tubes. The blood and milk samples, transported to the laboratory for obtaining sera, centrifuged at $3700 \mathrm{rpm}$ for 15 minutes, and a portion of skim milk was pipetted off from below the cream layer. Every serum sample saved in $1 \mathrm{ml}$, labeled and numbered, eppendorf tubes and frozen under $-20^{\circ} \mathrm{C} .3,24$

\section{IDEXX ELISA}

"The blood and milk serum samples of lactating cows were examined by indirect IDEXX ELISA kit for bTB (Mycobacterium bovis) according to the manufacturer's instructions (IDEXX laboratories). The serum samples and kit controls were diluted 1:50 in sample diluents that provided with the kit as a first step, then, $100 \mu \mathrm{L}$ was added into the wells and incubated at room temperature $\left(37^{\circ} \mathrm{C}\right)$ for 1 hour. This step was followed by removal of the contents of the wells by washing the plates with PBS Tween Buffer solution, 4 times after which $100 \mu \mathrm{L}$ of a monoclonal anti-bovine IgG - HRP conjugate was added into each well and incubated at room temperature for 30 minutes. Again, the plates were washed 4 times by a PBS Tween Buffer solution that followed by the addition of $100 \mu \mathrm{l}$ of tetramethylbenzidine substrate (TMB) into each well, and incubated for 15 minutes at room temperature. In direct, the further reactions were stopped by addition of $50 \mu \mathrm{L} \mathrm{H}_{2} \mathrm{SO}_{4}$ and the optical density (OD) value was read by using an ELISA microplate reader (BioTek, USA) at a wavelength of $450 \mathrm{~nm}$.

The IDEXX ELISA results were recorded as positives or negatives based on a sample to positive $(\mathrm{S} / \mathrm{P})$ ratio and the result of each sample are submitted to the following formula:

$\mathrm{S} / \mathrm{P}$ ratio $=\frac{\text { Sample Result at }(450)-\text { Mean of Negative Controls }}{\text { Mean of Positive Controls }- \text { Mean of Negative Controls }}$

Manufacturer's recommended cut-off is an S/P ratio of 0.3 . The $(\mathrm{S} / \mathrm{P})$ ratio $\geq 0.3$ is considered that the test was positive."

\section{Statistical Analyses}

All data were arranged and labeled with a computerized program (Word and Excel v. 2013), then transferred to the IBM SPSS (v. 23) to analysed by Chi-square test. Statistically, the significant differences were used at $(P>0.05)$ to compare between the results of blood and milk serum samples, and to detect the associations between infection and the clinical signs (25).

\section{Results}

During 8 months, the blood and milk serum samples of 119 lactating cows were tested by IDEXX ELISA test in 2 provinces, Wasit and Dhi-Qar, to detect the positive cases with M. bovis infections. According to (Table 1), 24/119 (20.16\%) were positives with blood serum samples testing while 18/119
(15.12\%) were positives with milk serum samples by IDEXX ELISA test.

Depending on the results of blood serums samples (Table 2), $16 / 70(22.85 \%)$ were positives with bTB in Wasit province and $8 / 49$ (16.32\%) positive cows in Dhi-Qar province. While in (Table 3) the results of milk serum samples were 11/70 (15.71\%) and $7 / 49(14.28 \%)$ in Wasit and Dhi-Qar provinces, respectively.

In Table 4 , the results of data collection and clinical case history examination in ${ }^{24}$ positive cows with blood testing

\begin{tabular}{llllll}
\hline Table 1. Total infected cases according to blood and milk \\
serum results
\end{tabular}

Horizontally, the different small letters refers to a significant difference at level $P<0.05$.

Table 2. Total infected cases by blood serum groups according to provinces results

\begin{tabular}{lccccc}
\hline \multirow{2}{*}{$\begin{array}{l}\text { Total tested } \\
\text { number }\end{array}$} & \multicolumn{3}{c}{ Total infected cases } \\
\cline { 2 - 3 } & \multicolumn{2}{c}{ Wasit / 70 Cows } & & \multicolumn{2}{c}{ Dhi-Qar / 49 Cows } \\
\cline { 2 - 3 } \cline { 5 - 6 } & No. & \% & & No. & \% \\
\hline 119 & 16 & $22.85^{\mathrm{a}}$ & & 8 & $16.32^{\mathrm{b}}$ \\
\hline
\end{tabular}

Horizontally, the different small letters refers to a significant difference at level $P<0.05$.

Table 3. Total infected cases by milk serum according to provinces
results

Horizontally, the different small letters refers to a significant difference at level $P<0.05$.

\begin{tabular}{lllrlrr}
\hline \multicolumn{3}{c}{ Table 4. Clinical signs of positives cows with blood and milk } \\
serum samples
\end{tabular}

Horizontally, the different small letters refers to a significant difference at level $P<0.05$. 
group and ${ }^{18}$ positive cows with milk testing group were as follow, respectively; the respiratory disorders (cough and/or dyspnea) were found in 5/24 (20.83\%) and 3/18 (16.66\%), continual decreasing in milk production in $7 / 24(29.16 \%)$ and 4/18 (22.22\%); emaciation in $9 / 24(37.5 \%)$ and $7 / 18(38.88 \%)$, rough hair coat in 5/24 (20.83\%) and 4/18 (22.22\%), repetitive reproductive problems (abortions, uterine discharges, infertility) in $3 / 24(12.5 \%)$ and $2 / 18(11.11 \%)$, persistent feces abnormalities (diarrhea or constipation) in $1 / 24(4.165)$ and $1 / 18$ (5.55\%), mastitis in 4/24 (16.66\%) and 3/18 (16.66\%), lymph nodes enlargement (locally or systemically) in $2 / 24$ $(8.33 \%)$ and $2 / 18(11.11 \%)$, and loss of appetite in $2 / 24(8.33 \%)$ and $1 / 18(5.55 \%)$.

\section{Discussion}

In countries that do not commence routine screening tests for their herds, their herds are expected to contain animals at different stages of tuberculosis. Therefore, for assaying their herds, the better use of serological test, IDEXX ELISA test would be useful in early detection and advance cases which otherwise cannot be detected by tuberculin skin test. ${ }^{26,19}$ In this study, bTB had an overall prevalence 24/119 (20.16\%) with blood testing group and 18/119 (15.12\%) with milk testing group. Thirteen cows were positives with both tests, while 11 and 5 cows, respectively, were positive to test in blood and milk groups only. Thus, IDEXX ELISA had a sensibility to detect the antibodies in blood more than in milk, and several causes may be concluded in the interpretation of this difference such as the individual differences in animal's antibody responses, lactation stage, time of milk collection, herd size, proportion of milk dilution, cutoff level changing, and the producing of nonspecific antibody responses to test antigens. ${ }^{20}$ However, the test sensitivity is increased markedly with severity of the disease. ${ }^{27}$ Also, the high relationship among an antibody's reactions in milk and blood had been reported, at same animal, in bTB and John's disease. ${ }^{28,29}$ As well as, milk might become, widely, extra-suitable after collection of it during the routine examination of herds. ${ }^{30}$ Milk can be contributed in identifying the diseased cattle, although about 50 percentage of technique's sensitivity would decrease. ${ }^{31}$ Also, it would be missed; apparently, their benefit through an examination of a few diseased cattle that persist at large groups. ${ }^{20}$

The results of Tables 2 and 3 revealed that in Wasit province, the morbidity rate was more than this reported in Dhi-Qar province. Although, the role of local spread of bTB in some areas is not well understood, bTB testing had a significant impact on the expansion and long distance spread of disease, especially on transmission to areas with relatively low incidence. ${ }^{32}$ A variable incidence of bTB may effect through several modes like the geographical position features; Agroecological system; public health condition for humans and animals; herd size, farm management and grazing practice; age, breed, gender and body condition score of animals; compelled organizing schemes of the veterinary departments; concurrent diseases, host genetic variation, immune suppression, cattle behavior, physiological status, cows scheme form, feeding system, treatments with control program, environments or weather, pathological variations. ${ }^{33-35}$

Whilst the respiratory disorders, emaciation, rough hair coat, decrease in milk production and presence of reproductive failures shows the most prevalent signs of positive cows in blood and milk groups; the enlargement of lymph nodes, loss of appetites and feces abnormalities manifested the lowers, with presence of some differences between both serum groups. These resultants were approval to studies revealed by various researchers. ${ }^{36-39}$ Historically, bTB is troublesome and tired to detect in depending, solely, on obvious symptoms particularly in advanced countries that had a low proportion of diseased cows with acutely intense infection, and the diagnosis is employ, mostly, through the tuberculin skin test or discovered after slaughter. ${ }^{40,41}$ In early stages of infection, the clinical signs are not visible, but with advance stages, the signs begin to appear in depending on species of animal, point of entry, sites of localization, and the afflicted organs. ${ }^{42}$ Many animals may be infected sub-clinically and remained asymptomatic until the development of disseminated lesions, or infected again with $M$. bovis; submitted to bad feeding, progress of age, and if undergo from more one infection by other pathogens. ${ }^{43-45}$ Referred that the most bTB infections, infrequently, shown to be diseased clinically and seems apparently healthy. The acuteness of infection in cattle is depending, generally, on several factors such as the infective dose, point of entry, troubled immunity, age, stress, and the genetic variation. ${ }^{24,46}$ Also, the high cattle density may provide a chance for incorporate throughout the unleash feeding on pasture or during persistence of healthy and diseased cattle with each other under commercial schemes with low nutrition that make these cattle very liable for diseases. ${ }^{47} \mathrm{~A}$ recent literature review concluded that the role of positive bTB cows, with minimal or no observed signs, is far from clear. ${ }^{48}$ "Despite the successes of the IDEXX ELISA in detection of infection with $M$. bovis, but the reliability of it is depending on several factors including the efficiency of testing procedure, mode of interpretation of result as well as the immunological responsiveness of the animal at the time of test. Furthermore, the negative results to test doesn't mean that the animal is not infected with M. bovis, while on the other hand, the positive results represented an immunological response that might be due to the current infections or a previous exposure to $M$. bovis but, may less commonly, due to the infection or exposure to other bacteria that share an antigens similar to those of M. bovis. ${ }^{{ }^{49,50}}$

\section{Acknowledgment}

I grant this work to my family for great supporting, contributing in completion of this work, and to everyone help me during collection samples, data, and providing me with required references.

\footnotetext{
References

1. Radostits OM, Gay CC, Hinchcliff KW, Constable PD. Veterinary Medicine: A textbook of the diseases of cattle, horses, sheep, pigs and goats. $10^{\text {th }}$ ed. Saunders Elsevier Company Ltd, London. Part 2, diseases associated with bacteria - IV. 2007; pp. 1007-1017.

2. Abubakar U, Ameh J, Abdulkadir I, Salisu I, Okaiyeto S, Kudi AC. Bovine tuberculosis in Nigeria: A review. Vet Res. 2011;4(1):24-27.
}

3. Gumi B, Schelling E, Firdessa R, Aseffa A, Tschopp R, Yamuah L, et al. Prevalence of bovine tuberculosis in pastoral cattle herds in the Oromia region, southern Ethiopia. Trop Anim Health Prod. 2011;43(6):1081-1087.

4. Smith BP. Large animal internal medicine. Elsevier Health Sciences.chapter 31, Diseases of respiratory systems. 2014; pp. 576 
5. Terefe D. Gross pathological lesions of bovine tuberculosis and efficiency of meat inspection procedure to detect-infected cattle in Adama municipal abattoir. J Vet Med Anim Health. 2014;6(2):48-53.

6. Sweeney RW. Pathogenesis of paratuberculosis. Vet Clin Food Anim Prac. 2011;27(3):537-546.

7. Brooks-Pollock E, Roberts GO, Keeling MJA. Dynamic model of bovine tuberculosis spread and control in Great Britain. Nature. 2014;511 (7508):228-231.

8. Murphy D, Gormley E, Costello E, O'Meara D, Corner LAL. The prevalence and distribution of Mycobacterium bovis infection in European badgers (Meles meles) as determined by enhanced post mortem examination and bacteriological culture. Res Vet Sci. 2010;88(1):1-5.

9. Michel AL, De Klerk LM, Pittius NCG, Warren RM, Van Helden PD. Bovine tuberculosis in African buffaloes: observations regarding Mycobacterium bovis shedding into water and exposure to environmental mycobacteria. BMC Vet Res. 2007;3(1):1.

10. Alvarez J, Perez AM, Bezos J, Casal C, Romero B, Rodriguez-Campos S, et al. Eradication of bovine tuberculosis at a herd-level in Madrid, Spain: study of within-herd transmission dynamics over a 12 year period. BMC Vet Res. 2012;8(1):1.

11. Hasso SA. Confirmed pathogens of cows and buffaloes in Iraq. Iraqi Journal of Veterinary Sciences. 2004;18(1):1-14.

12. Mudhar ASA. Application of tuberculin screening tests for determination the prevalence of bovine tuberculosis in Basra governorate/Iraq. Mirror Res Vet Sci Anim. 2015;4(3):1-8.

13. Andrews AH, Blowey RW, Boyd H, Eddy RG. Bovine medicine: diseases and husbandry of cattle. John Wiley and Sons. Part 2, Diseases, Growing cattle, Respiratory diseases. 2008;Ch.49, pp. 862-864.

14. Claridge J, Diggle P, McCann CM, Mulcahy G, Flynn R, McNair J, et al. Fasciola hepatica is associated with the failure to detect bovine tuberculosis in dairy cattle. Nat Commun. 2012;3:853.

15. Shitaye JE, Tsegaye W, Pavlik I. Bovine tuberculosis infection in animal and human populations in Ethiopia: a review. Veterinari Medicina- Praha. 2007;52(8):317.

16. Waters WR, Whelan AO, Lyashchenko KP, Greenwald R, Palmer MV, Harris BN, et al. Immune responses in cattle inoculated with Mycobacterium bovis, Mycobacterium tuberculosis, or Mycobacterium kansasii. Clin Vac Immunol. 2010;17(2):247-252

17. Whelan C, Shuralev E, Kwok HF, Kenny K, Duignan A, Good M, et al. Use of a multiplex enzyme - linked immunosorbent assay to detect a subpopulation of Mycobacterium bovis - infected animals deemed negative or inconclusive by the single intradermal comparative tuberculin skin test. J Vet Diagnos Invest. 2011;23(3):499-503.

18. Ameni $G$, Erkihun A. Bovine tuberculosis on small-scale dairy farms in Adama Town, central Ethiopia, and farmer awareness of the disease. Revue Scientifique et Technique-Office International des Epizooties. 2007;26(3):711-720

19. Hirpa E, Ameni G, Lawrence JC, Tafess K, Worku A, Sori T, et al. Performance evaluation of Mycobacterium bovis antibody test for the diagnosis of bovine tuberculosis in Ethiopia. 2014;5:9.

20. Buddle BM, Wilson T, Luo D, Voges H, Linscott R, Martel E, et al. Evaluation of a commercial enzyme-linked immunosorbent assay for the diagnosis of bovine tuberculosis from milk samples from dairy cows. clin Vac Immunol. 2013;20(12):1812-1816.

21. OIE, Procedure for registration of diagnostic kits abstract sheet IDEXX M.bovis antibody test kit, IDEXX laboratories, www.oie.int.Accessed. (2012).

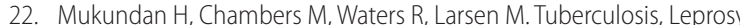
and Mycobacterial Diseases of Man and Animals: The Many Hosts of Mycobacteria. CABI. 2015; pp. 221-224.

23. Belić B, Cincović MR, Stojanović D, Kovačević Z, Medić S, Simić V. Hematology parameters and physical response to heat stress in dairy cows. Savremena poljoprivreda. 2010;59(1-2):161-166.

24. Mahmud MAA, Belal SMSH, Shoshe, NZ. Prevalence of Bovine Tuberculosis in Cattle in the Selected Upazila of Sirajganj District in Bangladesh. Bangladesh J Vet Med. 2014;12(2):141-145.

25. Petrie A, Watson P. Statistics for Veterinary and Animal Science, Second Edition. Ames: Blackwell Publishing. (2006); pp. 312.

26. WHO/IUATLD. Anti-tuberculosis drug resistance in the world. Fourth global report. WHO/HTM/TB/.394. Geneva, Switzerland: World Health Organization. (2008)
27. Mosaad AA, Abdel-Hamed AS, Fathalla SI, Ghazy AA, Elballal S, Elbagory A, et al. Sensitive and specific diagnostic assay for detection of tuberculosis in cattle. Global Veterinaria. 2012;8(6):555-564.

28. Lombard JE, Byrem TM, Wagner BA, McCluskey BJ. Comparison of milk and serum enzyme-linked immunosorbent assays for diagnosis of Mycobacterium avium subsp. paratuberculosis infection in dairy cattle. J Vet Diagn Invest. 2006;18:448-458.

29. Jeon BY, Kim SC, Je S, Kwak J, Cho JE, Woo JT, et al. Evaluation of enzyme-linked immunosorbent assay using milk samples as a potential screening test of bovine tuberculosis of dairy cows in Korea. Res Vet Sci. 2010;88:390-393

30. Waters WR, Buddle BM, Vordermeier HM, Gormley E, Palmer MV, Thacker TC, et al. Development and evaluation of an enzyme-linked immunosorbent assay for use in the detection of bovine tuberculosis in cattle. Clin Vac Immunol. 2011;18(11):1882-1888.

31. Marassi CD, Medeiros L, Figueiredo E, Fonseca LS, Duarte R, Paschoalin V, et al. A multidisciplinary approach to diagnose naturally occurring bovine tuberculosis in Brazil. Pesquisa Veterinária Brasileira. 2013:33(1):15-20.

32. Green DM, Kiss IZ, Mitchell AP, Kao RR. Estimates for local and movementbased transmission of bovine tuberculosis in British cattle. Proc R Soc Lond [Biol]. 2008;275(1638):1001-1005

33. Moiane I, Machado A, Santos N, Nhambir A, Inlamea O, Hattendorf J, et al. Prevalence of bovine tuberculosis and risk factor assessment in cattle in rural livestock areas of Govuro District in the Southeast of Mozambique. PloS one. 2014;9(3):e91527.

34. More SJ, Good M. Understanding and managing bTB risk: Perspectives from Ireland. Vet Microbiol. 2015:176(3):209-218.

35. Cezar RD, Lucena-Silva N, Filho AF, Borges Jde M, de Oliveira PR, Lúcio ÉC, et al. Molecular detection of Mycobacterium bovis in cattle herds of the state of Pernambuco, Brazil. BMC Vet Res. 2016;12(1):1.

36. Collins CH. The bovine tubercle bacillus. Br J Biomed Sci. 2000:57(3):234

37. Cassidy JP. The pathogenesis and pathology of bovine tuberculosis with insights from studies of tuberculosis in humans and laboratory animal models. Vet Microbiol. 2006;112(2):151-161.

38. Renwick AR, White PC, Bengis RG. Bovine tuberculosis in southern African wildlife: a multi-species host-pathogen system. Epidemiol Infect. 2007;135(04):529-540

39. Skuce RA, Allen AR, McDowell SW, Branch B. Bovine tuberculosis (TB): A review of cattle-to-cattle transmission, risk factors and susceptibility. Agri Food Biosci Ins, Belfast. 2011;1(3):32-37.

40. Fentahun T, Luke G. Diagnostic techniques of bovine tuberculosis: a review. African J Basic Appl Sci. 2012;4(6):192-199.

41. Ramos DF, Silva PE, Dellagostin OA. Diagnosis of bovine tuberculosis: review of main techniques. Brazilian J Biol, (AHEAD). 2015; http://dx.doi.org/ 10.1590/1519-6984.23613.

42. Green LE, Medley G. Cattle to cattle transmission of bovine tuberculosis: risk factors and dynamics. Cattle Practice. 2008;16(2):116-121.

43. Cosivi O, Meslin FX, Daborn CJ, Grange JM. Epidemiology of Mycobacterium bovis infection in animals and humans, with particular reference to Africa. Revue scientifique et technique (International Office of Epizootics). 1995; 14(3):733-746.

44. Donnelly C, Cox D. Bovine TB in cattle and badgers. Significance. 2007:4(4):164-167.

45. Collins JD. Tuberculosis in cattle: strategic planning for the future. Vet Microbiol. 2006;112(2):369-381.

46. Bojkovski J, Renata RE. The case of bovine tuberculosis at the slaughter house. Bulletin of University of Agricultural Sciences and Veterinary Medicine Cluj-Napoca. Vet Med. 2011;2:68

47. Adesokan HK, ljagbone IF, Oputa HE, Cadmus SIB, Stack JA. Serological survey of brucellosis in livestock animals and workers in Ibadan, southwestern, Nigeria. African J Biomed Res. 2006;9:163-168.

48. Sosnik A, Carcaboso ÁM, Glisoni RJ, Moretton MA, Chiappetta DA. New old challenges in tuberculosis: potentially effective nanotechnologies in drug delivery. Advanced Drug Deliv Rev. 2010;62(4):547-559.

49. Bermúdez HR, Rentería ET, Medina BG, Hori-Oshima S, De la Mora Valle A, López VG. Evaluation of a lateral flow assay for the diagnosis of Mycobacterium bovis infection in dairy cattle. J Immunoassay and Immunochem. 2012;33(1):59-65

50. BhanuRekha V, Gunaseelan L, Pawar G, Nassiri R, Bharathy S. Molecular detection of Mycobacterium tuberculosis from bovine milk samples. J Advan Vet Anim Res. 2014;2(1):80-83. 